\title{
PENGARUH STORE ATMOSPHERE TERHADAP MINAT BELI KONSUMEN PADA DISTRO THREE SECOND DI KOTA MATARAM
}

\author{
Rian Indranopa ${ }^{1}$, Agus Hermanto ${ }^{2}$ \\ 1,2Faculty of Business and Low, Technology University of Mataram, Indonesia. \\ E-mail: rian.indranopa@gmail.com \\ agushermanto2511@gmail.com
}

\begin{tabular}{|c|c|}
\hline ARTICLE INFO & ABSTRACT \\
\hline Keywords: & The purpose of this study was to determine how the influence of \\
\hline Store Atmosphere; Buying Interest & the store atmosphere on consumer buying interest. This type of \\
\hline Kata Kunci : & $\begin{array}{l}\text { research is causal associative (cause and effect), and the } \\
\text { determination of respondents using incidental sampling of } 160\end{array}$ \\
\hline Suasana Toko; Minat Beli & $\begin{array}{l}\text { respondents. Data collection techniques with interviews, } \\
\text { observations and questionnaires. To analyze the effect of store }\end{array}$ \\
\hline How to cite: & atmosphere used Classical Assumption Test, Multiple Linear \\
\hline Indranopa, R., Hermanto, A., (2021). & Regression Analysis and Multiple Coefficient of Determination \\
\hline $\begin{array}{l}\text { Pengaruh Store Atmosphere Terhadap } \\
\text { Minat Beli Konsumen pada Distro Three }\end{array}$ & $(R 2)$. \\
\hline $\begin{array}{l}\text { Second di Kota Mataram. JMM UNRAM, } \\
\text { 10(4), 236-246 }\end{array}$ & $\begin{array}{l}\text { Tujuan penelitian ini adalah untuk mengetahui bagaimana } \\
\text { Pengaruh Store Atmosphere Terhadap Minat Beli Konsumen. } \\
\text { Jenis penelitian ini bersifat asosiatif kausal (sebab akibat), dan }\end{array}$ \\
\hline $\begin{array}{l}\text { DOI: } \\
\text { https://doi.org/10.29303/jmm.v10i4.672 }\end{array}$ & $\begin{array}{l}\text { penentuan responden menggunakan sampling insidental } \\
\text { terhadap } 160 \text { orang responden. Teknik pengumpulan data }\end{array}$ \\
\hline \multirow{4}{*}{$\begin{array}{lc}\text { Dikumpulkan : } 05 \text { November } 2021 \\
\text { Direvisi } & : 16 \text { November } 2021 \\
\text { Dipublikasi } & : 23 \text { November } 2021\end{array}$} & Untuk menganalisis pengaruh store atmosphere digunakan $\mathrm{Uji}$ \\
\hline & Asumsi Klasik, Analisis Regresi Linier Berganda dan Koefisien \\
\hline & Determinasi Berganda $\left(R^{2}\right)$. \\
\hline & $\begin{array}{l}\text { Copyright } \odot 2021 \text {. Rian Indranopa, Agus Hermanto. All } \\
\text { rights reserved. }\end{array}$ \\
\hline
\end{tabular}

\section{PENDAHULUAN}

Persaingan distro semakin ketat khususnya di Kota Mataram. Salah satunya distro Three Second yang merupakan pelaku bisnis dalam bidang pakaian yang berkembang dan menawarkan produk yang tidak kalah menarik satu dengan yang lainnya dengan tujuan untuk merebut hati konsumen dalam melakukan pembelian. Menghadapi persaingan bisnis dalam merebut hati konsumen untuk melakukan pembelian, salah satu strategi pemasaran yang diterapkan oleh distro Three Second adalah memperhatikan store atmosphere yang menjadi ciri khas tersendiri antara distro lainnya.

Jumlah remaja di kota Mataram yaitu sebanyak 130.856 orang, ini menjadi potensi yang besar sebagai target pasar distro-distro di Mataram (BPS Kota Mataram). Selain itu, dari wawancara dan pengamatan awal peneliti kepada pihak distro menyebutkan bahwa 
pengunjung yang datang dari luar Kota Mataram berkisar antara 15\% sampai dengan 25\% dari jumlah remaja yang ada di Kota Mataram.

Menghadapi persaingan bisnis dalam merebut hati konsumen untuk melakukan pembelian, salah satu strategi pemasaran yang diterapkan oleh distro adalah memperhatikan suasana toko (store atmosphere) yang menjadi ciri khas tersendiri antara distro satu dengan distro lainnya, semua ingin menampilkan identitasnya masingmasing. Yang menjadi hal yang menarik lagi ketika berkunjung ke salah satu distro adalah penataan tempat, barang maupun tata cahaya yang di setting dengan sangat menarik. Lokasi distro yang kebanyakan tidak terlalu besar dan luas bisa disulap menjadi tempat berbelanja busana yang sangat nyaman untuk para calon pembeli yang berkunjung dengan variasi warna yang menarik untuk memberi kenyamanan setiap orang yang datang untuk membeli atau sekedar mencari tahu tren busana anak muda jaman sekarang. Sepatu, baju, kaos, sabuk, dompet, topi dan lain-lain di jual dengan harga yang disesuaikan dengan isi dompet remaja. Inilah yang membuat ketatnya persaingan antar distro di Mataram.

\section{KAJIAN PUSTAKA}

\subsection{Store Atmosphere (Suasana Toko)}

Menurut Lamb, hair, McDaniel (2001:105) Store atmosphere yaitu kesan keseluruhan yang disampaikan oleh tata letak fisik toko, dekorasi, dan lingkungan sekitarnya. Gilbert dalam Foster (2008:61) menjelaskan bahwa atmosphere tokomerupakan kombinasi dari pesan secara fisik yang telah direncanakan, atmosphere toko dapat digambarkan sebagai perubahan terhadap perancangan lingkungan pembelian yang menghasilkan efek emosional khusus yang dapat menyebabkan konsumen melakukan tindakan pembelian.

Menurut Alma (2011:62) perubahan terhadap atmosphere toko harus selalu dirancang agar tidak membosankan, langganan tetap setia, dan mengatasi para saingan. Jika konsumen bosan dengan suasana toko kemungkinan besar mereka akan beralih ke toko lain. beberapa ciri dari store atmosphere ialah sebagai berikut:

a. Eksterior Toko, meliputi meliputi keseluruhan bangunan fisik yang dapat di lihat dari luar, bentuk bangunan, warna dan model. Desain eksterior merupakan bagian fisik yang berperan kepada konsumen untuk membayangkan seperti apa toko yang akan mereka masuki.

b. Bagian depan toko, ini harus ditata dengan rapi, indah, dan mengesankan calon konsumen. Bagian depan toko ini merupakan bagian penting yang mendapat sorotan pertama, dan menimbulkan daya tarik tersendiri agar konsumen tergerak masuk ke dalam toko.

c. Etalase, ini harus menarik, barang dipajang secara beraturan dan rapi, serasi warna dan bentuknya.

d. Suasana sekeliling toko, apakah banyak toko lain atau tidak. Apabila banyak toko lain, ini dapat berakibat akan muncul kanibalisme atau sinergi. Kanibalisme artinya satu toko dengan toko yang lain saling mematikan karena faktor persaingan. Namun kebanyakan komplek pertokoan menjadi suatu sinergi saling melengkapi diantara toko sekelilingnya, dan menimbulkan keuntungan berupa daya tarik dari masyarakat berkunjung ke pusat bisnis tersebut. Ini sangat tergantung pada pihak manajemen, apaka ia dapat mengambil manfaat dari banyaknya toko lain disekeliling tokonya.

e. Sarana parkir, apakah tersedia cukup lahan, keteraturandan keamanan parkir. Apakah gratis, atau ditarik sewa parkir jam-jaman dsb. 
f. Unsur interior, ini menyangkut banyak hal seperti desain, estetika, penerangan, warna, lalu lintas internal, sirkulasi udara, kebersihan, kesejukan, tata letak, pengelompokan produk, arah/penunjuk, dan lokasi kasir.

Menurut Barry dan Evans dalam Meldarianda (2010:99), “Atmosphere can be divided into several elements: exterior, general interior, store layout, and displays." Cakupan Store atmosphere ini meliputi: bagian luar toko, bagian dalam toko, tata letak ruangan, dan pajangan (interior point of interest display), akan dijelaskan lebih lanjut dibawah ini:

1. Exterior (Bagian Luar Toko)

Karakteristik exterior mempunyai pangaruh yang kuat pada citra toko tersebut, sehingga harus direncanakan dengan sebaik mungkin. Kombinasi dari exterior ini dapat membuat bagian luar toko menjadi terlihat unik, menarik, menonjol dan mengundang orang untuk masuk kedalam toko.

2. General Interior (Bagian Dalam Toko)

Yang paling utama yang dapat membuat penjualan setelah pembeli berada di toko adalah display. Desain interior dari suatu toko harus dirancang untuk memaksimalkan visual merchandising. Display yang baik yaitu yang dapat menarik perhatian pengunjung dan membantu meraka agar mudah mengamati, memeriksa, dan memilih barang dan akhirnya melakukan pembelian. Ada banyak hal yang akan mempengaruhi persepsi konsumen pada toko tersebut.

3. Layout Ruangan (Tata Letak Toko)

Pengelola toko harus mempunyai rencana dalam penentuan lokasi dan fasilitas toko. Pengelola toko juga harus memanfaatkan ruangan toko yang ada seefektif mungkin.

4. Interior Point of Interest Display (Dekorasi Pemikat Dalam Toko)

Interior point of interest display mempunyai dua tujuan, yaitu memberikan informasi kepada konsumen dan menambah store atmosphere, hal ini dapat meningkatkan penjualan dan laba toko.

\subsection{Minat Beli Konsumen}

Pengertian minat beli konsumen menurut Kotler (2005:205) adalah sesuatu yang timbul setelah menerima rangsangan dari produk yang dilihatnya, dari sana timbul ketertarikan untuk mencoba produk tersebut sampai pada akhirnya timbul keinginan untuk membeli agar dapat memilikinya. Menurut Assael (2002:53) menyatakan bahwa: "Minat beli konsumen timbul dan terbentuk setelah konsumen melakukan evaluasi terlebih dahulu terhadap suatu merek dan akan melakukan pembelian terhadap merek yang dapat memberikan tingkat paling tinggi dari kepuasan yang diharapkan".

Assael (2002:60) menjelaskan bahwa titik tolak untuk memahami perilaku pembelian konsumen adalah melakukan model stimulasi AIDA yang berusahan menggambarkan tahap-tahap suatu rangsangan tertentu yang diberikan oleh para pemasar, yaitu sebagai berikut:

a. Attention, yaitu timbulnya perhatian konsumen terhadap suatu usaha pemasaran yang diberikan oleh pemasar.

b. Interest, yatu munculnya minat beli konsumen tertarik terhadap objek yang dikenalkan oleh suatu pemasar

c. Desire, yaitu setelah merasa tertarik, timbul hasrat atau keinginan untuk memiliki objek tersebut.

d. Action, yaitu tindakan yang muncul setelah tiga tahapan diatas, yaitu melakukan pembelian.

Minat beli konsumen merupakan masalah yang sangat kompleks namun harus tetap menjadi perhatian pemasar. Minat konsumen untuk membeli dapat muncul sebagai 
akibat dari adanya rangsangan (stimulus) yang ditawarkan oleh perusahaan. Masingmasing stimulus tersebut dirancang untuk menghasilkan tindakan pembelian konsumen.

\subsection{Perumusan Hipotesis}

Berdasarkan latar belakang dan landasan teori yang yelah diuraikan, maka dapat dirumuskan hipotesis sebagai berikut:

a. Diduga store atmosphere yang terdiri dari exterior, general interior, store layout, dan interior display berpengaruh signifikan secara parsial terhadap minat beli konsumen pada Distro Three Second di Kota Mataram.

b. Diduga store atmosphere yang terdiri dari exterior, general interior, layout, dan interior display berpengaruh signifikan secara simultan terhadap minat beli konsumen pada Distro Three Second di Kota Mataram.

c. Diduga variabel store layout mempunyai pengaruh dominan terhadap minat beli konsumen pada Distro Three Second di Kota Mataram.

\section{METODE PENELITIAN}

Jenis penelitian yang digunakan adalah penelitian asosiatif kausal (sebab akibat), penelitian untuk mengetahui pengaruh variabel independen dalam hal ini unsur-unsur store atmosphere antara lain exterior, general interior, store layout, dan Interior display terhadap variabel dependen dalam hal ini minat beli konsumen pada distro Three Second di Kota Mataram.

Metode pengumpulan data yang digunakan dalam penelitian ini adalah metode sample survey. Yang mana sample survey adalah suatu prosedur dimana hanya sebagian populasi saja yang diambil dan digunakan untuk menentukan sifat serta ciri yang dikehendaki dari populasi. Populasi dalam penelitian ini adalah siapa saja yang berkunjung pada distro Three Second di Mataram. Dalam hal ini peneliti mengambil sampel sebanyak 160 responden, jumlah sampel tersebut juga telah memenuhi persyaratan penarikan sampel yang disarankan yaitu 5-10 kali jumlah item pertanyaan yang terdapat pada kuesioner (Ghozali dan Fuad, 2005). Berdasarkan jumlah item pertanyaan dalam penelitian ini adalah 16 pertanyaan, dengan demikian jumlah sampel adalah $10 \times 16=160$ orang.

\section{HASIL DAN PEMBAHASAN}

\subsection{Gambaran Umum Lokasi}

Mataram merupakan ibu kota Provinsi Nusa Tenggara Barat. Kota Mataram terdiri dari 6 Kecamatan yaitu Kecamatan Ampenan, Cakranegara, Mataram, Pejanggik, Selaparang, dan Sekarbela dengan 50 kelurahan dan 297 Lingkungan. Kota Mataram terletak pada $08^{\circ} 33^{\prime}-08^{\circ} 38^{\prime}$ LS dan $116^{\circ} 04^{\prime}-116^{\circ} 10^{\prime}$ BT dan luas wilayah $61,30 \mathrm{~km}^{2}$ dengan batas-batas Kabupaten Lombok Barat di bagian Utara, Timur, dan Selatan, serta Selat Lombok di bagian Barat. Selain itu, Mataram juga menjadi pusat perdagangan khususnya distro. Salah satunya adalah Distro Three Second di Jalan Panca Usaha No.29 Cakranegara.

\subsection{Gambaran Umun Responden}

Pada penelitian ini kuesioner disebarkan kepada 160 orang yang melakukan kunjungan pada distro-distro di Mataram. Gambaran umum responden berdasarkan 
alamat, usia, jenis kelamin, pendidikan terakhir, dan pekerjaan responden, yang diperoleh dari kuesioner yang dibagikan ke responden. Maka diperoleh data statistik sebagai berikut: 4.2.1. Klasifikasi Responden Berdasarkan Alamat Responden

Berdasarkan hasil penelitian yang telah dilakukan, maka klasifikasi responden menurut alamat responden dapat diidentifikasikan sebagai berikut :

Tabel 4.1 Data Responden Berdasarkan Alamat

\begin{tabular}{|l|l|r|r|}
\hline No & \multicolumn{1}{|c|}{ Alamat } & Frekuensi (Orang) & \multicolumn{1}{c|}{ Persentase (\%) } \\
\hline 1 & Kota Mataram & 61 & 38,1 \\
\hline 2 & Lombok Barat & 21 & 13,1 \\
\hline 3 & Lombok Tengah & 30 & 18,8 \\
\hline 4 & Lombok Timur & 27 & 16,9 \\
\hline 5 & Lombok Utara & 6 & 3,8 \\
\hline 6 & Sumbawa & 9 & 5,6 \\
\hline 7 & Bima & 4 & 2,5 \\
\hline 8 & Dompu & 2 & 1,3 \\
\hline & Jumlah & 160 & 100 \\
\hline
\end{tabular}

Sumber: Data diolah

Berdasarkan tabel di atas dapat diketahui bahwa sebagian besar responden beralamatkan di Kota Mataram yakni sebesar 38,1\%, sisanya beralamatkan di Lombok Barat sebesar 13,1\%, beralamatkan di Lombok Tengah sebesar 18,8\%, beralamatkan di Lombok Timur sebesar 16,9\%, beralamatkan di Lombok Utara sebesar 3,8\%, beralamatkan di Sumbawa sebesar 5,6\%, beralam di Bima 2,5\% dan beralamatkan di Dompu sebesar $1,3 \%$. Data tersebut menunjukan bahwa responden didominasi berasal dari Kota Mataram, hal ini disebabkan karena lokasi dari Distro Three Second tersebut berada di Kota Mataram.

\subsubsection{Klasisikasi Responden Berdasarkan Usia}

Berdasarkan hasil tabulasi menurut usia, responden dalam penelitian ini dapat diklasifikasikan sebagai berikut :

Tabel 4.2 Data Responden Berdasarkan Tingkat Usia

\begin{tabular}{|l|l|r|r|}
\hline \multirow{2}{*}{ No } & Usia ( Tahun ) & Jumlah (Orang) & Persentase (\%) \\
\hline 1 & $15-20$ & 16 & 10,0 \\
\hline 2 & $21-25$ & 135 & 84,4 \\
\hline 3 & $26-30$ & 9 & 5,6 \\
\hline \multicolumn{2}{|c|}{ Jumlah } & 160 & 100 \\
\hline
\end{tabular}

Sumber: Data diolah

Berdasarkan tabel di atas, dapat diketahui bahwa sebagian besar responden berusia antara $21-25$ tahun yaitu sebesar $84,4 \%$, sisanya responden yang berusia antara 15 20 tahun yaitu sebesar 10,0\% dan responden yang berusia antara 26-30 tahun yaitu sebesar $5,6 \%$. Hal ini menunjukkan bahwa responden terbanyak yaitu responden yang berusia antara 21-25 tahun, karena pada usia tersebut mereka dituntut untuk memenuhi keinginan untuk selalu tampil gaya.

\subsubsection{Klasifikasi Responden Berdasarkan Jenis Kelamin}

Berdasarkan hasil penelitian yang telah dilakukan, maka klasifikasi responden menurut jenis kelamin dapat diidentifikasikan sebagai berikut : 
Tabel 4.3 Data Responden Berdasarkan Jenis Kelamin

\begin{tabular}{|l|l|r|r|}
\hline No & Jenis Kelamin & Jumlah (Orang) & Persentase (\%) \\
\hline 1 & Pria & 112 & 70,0 \\
\hline 2 & Wanita & 48 & 30,0 \\
\hline \multicolumn{2}{|c|}{ Jumlah } & 160 & 100 \\
\hline
\end{tabular}

Sumber: Data diolah

Berdasarkan tabel di atas, dapat diketahui bahwa sebagian besar responden adalah responden yang berjenis kelamin wanita yaitu sebesar $70,0 \%$ dan sisanya responden yang berjenis kelamin pria yaitu sebesar $30,0 \%$. Hal ini menunjukkan bahwa responden yang berjenis kelamin pria lebih banyak dibandingkan degan responden yang berjenis kelamin wanita, karena pada umumnya Distro Three Second lebih banyak menyediakan jenis produk untuk pria dibandingkan jenis produk untuk wanita.

\subsubsection{Klasifikasi Responden Berdasarkan Tingkat Pendidikan}

Berdasarkan tingkat pendidikan yang ditempuh, maka responden dalam penelitian ini dapat diklasifikasikan seperti pada tabel berikut ini :

Tabel 4.4 Data Responden Berdasarkan Tingkat Pendidikan

\begin{tabular}{|l|l|r|r|}
\hline No & Pendidikan & Jumlah (Orang) & \multicolumn{1}{|c|}{ Persentase (\%) } \\
\hline 1 & SLTP & 17 & 10,6 \\
\hline 2 & SMA & 118 & 73,8 \\
\hline 3 & D3 & 4 & 2,5 \\
\hline 4 & S1 & 21 & 13,1 \\
\hline \multicolumn{2}{|c|}{ Jumlah } & 160 & 100 \\
\hline
\end{tabular}

Sumber: Data diolah

Dari tabel di atas menunjukkan bahwa sebagian besar responden memiliki pendidikan terakhir SMA yaitu sebesar $73,8 \%$, sisanya responden yang memiliki pendidikan terakhir SLTP yaitu sebesar 10,6\%, responden yang memiliki pendidikan terakhir D3 yaitu sebesar 2,5\%, dan responden yang memiliki pendidikan terakhir S1 sebesar yaitu 13,1\%. Dari data tersebut terlihat bahwa responden yang paling banyak yaitu didominasi oleh responden yang memiliki pendidikan terakhir SMA.

\subsubsection{Klasifikasi Responden Berdasarkan Jenis Pekerjaan}

Berdasarkan jenis pekerjaannya, responden dalam penelitian ini dapat diklasifikasikan sebagai berikut :

Tabel 4.5 Data Responden Berdasarkan Pekerjaan

\begin{tabular}{|l|l|r|r|}
\hline No & Jenis Pekerjaan & Jumlah (Orang) & Persentase (\%) \\
\hline 1 & Pelajar & 17 & 10,6 \\
\hline 2 & Mahasiswa & 115 & 71,9 \\
\hline 3 & Swasta & 23 & 14,4 \\
\hline 4 & PNS & 5 & 3,1 \\
\hline \multicolumn{2}{|c|}{ Jumlah } & 160 & 100 \\
\hline
\end{tabular}

Sumber: Data diolah

Berdasarkan tabel di atas menunjukkan bahwa sebagian besar responden yang memiliki pekerjaan sebagai mahasiswa yaitu sebesar $71,9 \%$, sisanya responden yang memiliki pekerjaan sebagai pelajar yaitu sebesar 10,6\%, responden yang memiliki pekerjaan sebagai swasta yaitu sebesar $14,4 \%$ dan responden yang memiliki pekerjaan sebagai PNS yaitu sebesar 3,1\%. Dari data tersebut dapat diketahui bahwa responden didominasi oleh responden yang memiliki pekerjaan sebagai mahasiswa. 


\subsection{Analisis Data}

\subsubsection{Uji Validitas dan Reabilitas}

\subsubsection{Uji Validitas}

Validitas/ketepataan digunakan untuk mengetahui kelayakan butir-butir dalam suatu item pertanyaan penelitian. Suatu item pertanyaan apabila memiliki nilai positif > 0.3, maka item pertanyaan tersebut dinyatakan valid/tepat. Tabel berikut ini akan menyajikan nilai validitas. Data yang telah diperoleh dan diolah dengan bantuan program SPSS 16.0 for Windows.

Tabel 4.6 Hasil Uji Validitas

\begin{tabular}{|l|l|l|l|c|}
\hline Variabel & Pertanyaan & Korelasi Pearson & Nilai Kritis & Ket \\
\hline \multirow{3}{*}{ Exterior (X1) } & Pertanyaan 1 & 0,631 & 0,3 & Valid \\
\cline { 2 - 5 } & Pertanyaan 2 & 0,513 & 0,3 & Valid \\
\cline { 2 - 5 } & Pertanyaan 3 & 0,453 & 0,3 & Valid \\
\hline \multirow{3}{*}{ General Interior (X2) } & Pertanyaan 1 & 0,548 & 0,3 & Valid \\
\cline { 2 - 5 } & Pertanyaan 2 & 0,631 & 0,3 & Valid \\
\cline { 2 - 5 } & Pertanyaan 3 & 0,377 & 0,3 & Valid \\
\hline \multirow{3}{*}{ Store Layout (X3) } & Pertanyaan 1 & 0,548 & 0,3 & Valid \\
\cline { 2 - 5 } & Pertanyaan 2 & 0,546 & 0,3 & Valid \\
\cline { 2 - 5 } & Pertanyaan 3 & 0,497 & 0,3 & Valid \\
\hline \multirow{3}{*}{ Interior Display (X4) } & Pertanyaan 1 & 0,410 & 0,3 & Valid \\
\cline { 2 - 5 } & Pertanyaan 2 & 0,349 & 0,3 & Valid \\
\cline { 2 - 5 } & Pertanyaan 3 & 0,356 & 0,3 & Valid \\
\hline \multirow{3}{*}{$\begin{array}{l}\text { Minat Beli Konsumen } \\
\text { (Y) }\end{array}$} & Pertanyaan 1 & 0,701 & 0,3 & Valid \\
\cline { 2 - 5 } & Pertanyaan 2 & 0,469 & 0,3 & Valid \\
\cline { 2 - 5 } & Pertanyaan 4 & 0,383 & 0,3 & Valid \\
\cline { 2 - 5 } & Pertanyaan 4 & 0,397 & & \\
\hline
\end{tabular}

\section{Sumber: Data diolah}

\subsubsection{Uji Reabilitas}

Uji reliabilitas digunakan untuk mengukur konsistensi dari variabel pada instrumen. Butir pertanyaan pada variabel dalam suatu instrumen dikatakan reliabel atau terpercaya apabila jawaban responden adalah konsisten atau stabil dari waktu ke waktu. Suatu konstruk atau variabel dikatakan reliabel jika memberikan nilai Cronbach Alpha $\geq$ 0,60 . Adapun hasil uji reliabilitas dari instrumen yang digunakan dalam penelitian ini ialah sebagai berikut:

Tabel 4.7 Hasil Uji Reliabilitas

\begin{tabular}{|l|l|l|l|}
\hline \multicolumn{1}{|c|}{ Variabel } & Cronbach Alpha & Nilai Kritis & Keterangan \\
\hline Exterior (X1) & 0,621 & 0,6 & Reliabel \\
\hline General Interior (X2) & 0,668 & 0,6 & Reliabel \\
\hline Store Layout (X3) & 0,608 & 0,6 & Reliabel \\
\hline Interior Display (X4) & 0,665 & 0,6 & Reliabel \\
\hline Keputusan Pembelian (Y) & 0,625 & 0,6 & Reliabel \\
\hline
\end{tabular}

\section{Sumber: Data diolah}

\subsubsection{Uji Asumsi Klasik}

Tahap selanjutnya dalam analisis data adalah melakukan uji asumsi klasik yang terdiri dari: uji normalitas data, uji multikolinieritas, uji heteroskedastisitas dan uji Autokorelasi. Adapun hasil yang didapatkan yaitu: 1). Pada uji normalitas, distribusi data pada penelitian ini adalah normal karena rasio skewness dan rasio kurtosis berada di antara -2 hingga $+2 ; 2$ ). Pada uji multikolinieritas, model regresi tidak terjadi multikolinieritas karena nilai VIF masing-masing variabel penelitian $<10$ dan nilai Tolerance masing-masing variabel lebih dari 0,$1 ; 3)$. Pada uji heteroskedastisitas, tidak 
terjadi masalah heteroskedastisitas pada model regresi karena nilai signifikansi ke empat variabel independen lebih dari 0,$05 ; 4)$. Pada uji autokorelasi menunjukkan bahwa tidak terjadi autokorelasi karena $\mathrm{dU}<\mathrm{DW}<4-\mathrm{dU}$.

\subsection{Regresi Linier Berganda}

Metode ini digunakan untuk mengetahui pengaruh variabel exterior, general interior, store layout, dan interior display terhadap minat beli konsumen pada Distro Three Second di Kota Mataram. Proses analisis regresi berganda tersebut menggunakan bantuan program software komputer yaitu SPSS.

Tabel 4.8 Hasil Analisis Regresi Linier Berganda

\begin{tabular}{|c|c|c|c|c|c|c|c|c|}
\hline \multicolumn{9}{|c|}{ Coefficients } \\
\hline & \multirow[b]{2}{*}{ Model } & \multicolumn{2}{|c|}{$\begin{array}{l}\text { Unstandardized } \\
\text { Coefficients }\end{array}$} & \multirow{2}{*}{$\begin{array}{c}\begin{array}{c}\text { Standardized } \\
\text { Coefficients }\end{array} \\
\text { Beta }\end{array}$} & \multirow[b]{2}{*}{$\mathrm{t}$} & \multirow[b]{2}{*}{ Sig. } & \multicolumn{2}{|c|}{ Collinearity Statistics } \\
\hline & & B & Std. Error & & & & Tolerance & VIF \\
\hline \multirow[t]{5}{*}{1} & (Constant) & 7.887 & 1.610 & & 4.898 & .000 & & \\
\hline & $\mathrm{X} 1$ & .058 & .099 & .044 & .592 & .554 & .959 & 1.043 \\
\hline & $\mathrm{X} 2$ & .137 & .096 & .107 & 1.427 & .156 & .966 & 1.035 \\
\hline & $\mathrm{X} 3$ & .239 & .086 & .224 & 2.771 & .006 & .823 & 1.215 \\
\hline & $\mathrm{X} 4$ & .275 & .096 & .229 & 2.873 & .005 & .847 & 1.180 \\
\hline & endent Vari & ble: Y & & & & & & \\
\hline
\end{tabular}

Sumber: Data diolah

\subsection{Koefisien Determinasi Berganda $\left(\mathbf{R}^{2}\right)$}

Koefisien determinasi $\left(\mathrm{R}^{2}\right)$ pada intinya mengukur seberapa jauh kemampuan model dalam menerangkan variasi variabel independen. Dari perhitungan dengan menggunakan program SPSS diperoleh hasil sebagai berikut:

Tabel 4.9 Hasil Koefisien Determinasi Berganda $\left(\mathrm{R}^{2}\right)$

\begin{tabular}{|l|c|l|l|l|l|}
\hline \multicolumn{7}{|c|}{ Model Summary } \\
\hline Model & $\mathrm{R}$ & R Square & $\begin{array}{l}\text { Adjusted R } \\
\text { Square }\end{array}$ & $\begin{array}{l}\text { Std. Error of } \\
\text { the Estimate }\end{array}$ & $\begin{array}{c}\text { Durbin- } \\
\text { Watson }\end{array}$ \\
\hline 1 & $.404^{\mathrm{a}}$ & .163 & .142 & 1.930 & 2.056 \\
\hline a. Predictors: (Constant), X4, X1, X2, X3 & & \\
\hline \\
b. Dependent Variable: Y \\
\multicolumn{7}{|l}{ Sumber: Data diolah }
\end{tabular}

\subsection{Uji Hipotesis}

\subsubsection{Uji Parsial (Uji t)}

Uji t digunakan untuk mengetahui signifikansi atau kuat tidaknya masing-masing variabel diantaranya variabel exterior, general interior, store layout, dan interior display berpengaruh signifikansi atau tidak terhadap minat beli konsumen pada Distro Three Second di Kota Mataram. Berikut hasil perhitungan $t$ hitung serta tingkat signifikansi masing-masing indikator dari variabel $X$ terhadap variabel $Y$ : 


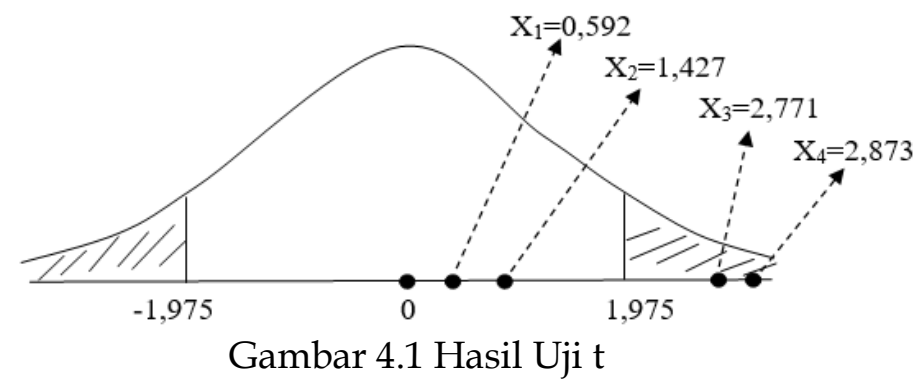

\subsubsection{Uji Simultan (Uji F)}

Uji $\mathrm{F}$ dilakukan untuk mengetahui tingkat signifikansi pengaruh variabel bebas yang terdiri dari exterior, general interior, store layout dan interior display terhadap variabel terikat yaitu minat beli konsumen. Berikut hasil pengujian ini dapat dilihat pada tabel bawah ini:

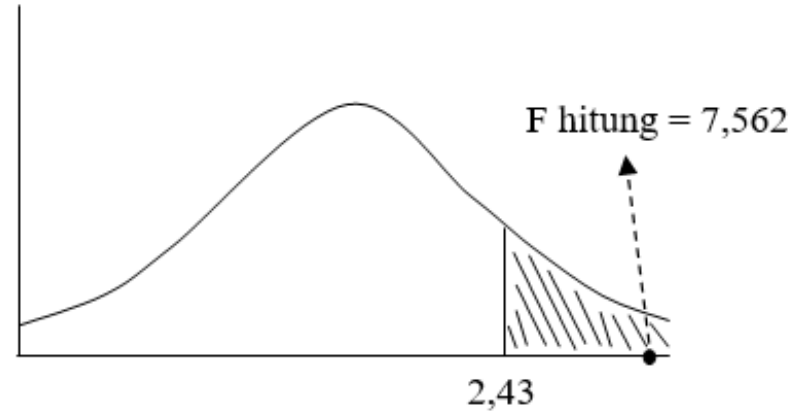

\subsubsection{Uji Dominan}

Gambar 4.2 Hasil Uji Simultan Model Regresi Berganda

Untuk mengetahui variabel yang memiliki pengaruh paling dominan dapat dilihat pada kolom standardized coefficients Beta yaitu koefisien dari masing-masing variabel bebas. Untuk mengatahui tentang variabel yang memiliki pengaruh dominan dapat dilihat pada tabel Coefficient di bawah ini:

Tabel 4.10 Hasil Uji Dominan Model Regresi Berganda

\begin{tabular}{|c|c|c|c|c|c|c|c|c|}
\hline \multicolumn{9}{|c|}{ Coefficients $^{a}$} \\
\hline \multirow{2}{*}{\multicolumn{2}{|c|}{ Model }} & \multicolumn{2}{|c|}{$\begin{array}{c}\text { Unstandardized } \\
\text { Coefficients }\end{array}$} & \multirow{2}{*}{\begin{tabular}{|c|}
$\begin{array}{c}\text { Standardize } \\
\mathrm{d} \\
\text { Coefficients }\end{array}$ \\
Beta \\
\end{tabular}} & \multirow[b]{2}{*}{$\mathrm{T}$} & \multirow[b]{2}{*}{ Sig. } & \multicolumn{2}{|c|}{$\begin{array}{l}\text { Collinearity } \\
\text { Statistics }\end{array}$} \\
\hline & & B & $\begin{array}{l}\text { Std. } \\
\text { Error }\end{array}$ & & & & Tolerance & VIF \\
\hline \multirow[t]{4}{*}{1} & (Constant & 7.887 & 1.610 & & 4.898 & .000 & & \\
\hline & $\mathrm{X} 1$ & .058 & .099 & .044 & .592 & .554 & .959 & 1.043 \\
\hline & $\mathrm{X} 2$ & .137 & .096 & .107 & 1.427 & .156 & .966 & 1.035 \\
\hline & $\mathrm{X} 3$ & .239 & .086 & .224 & 2.771 & .006 & .823 & 1.215 \\
\hline & $\mathrm{X} 4$ & .275 & .096 & .229 & 2.873 & .005 & .847 & 1.180 \\
\hline & endent Varia & able: $Y$ & & & & & & \\
\hline
\end{tabular}

Sumber: Data diolah

\subsection{Pembahasan}

Dari hasil penelitian ini, ditemukan bahwa Variabel X3 (Store Layout) dan X4 (Interior Display) berpengaruh signifikan terhadap Variabel Y (Minat Beli Konsumen). Hasil dari penelitian ini selaras dengan penelitian yang dilakukan oleh Meldarianda (2010) yang 
dilakukan di Bandung, Purwaningsih (2013) yang dilakukan di Kebumen, Nuridja (2014) yang dilakukan di Kecamatan Nusa Penida, Sari (2014) yang dilakukan di Semarang dan Zayyana (2014) yang dilakukan di Kota Mataram.

Sendangkan dari hasil penelitian ini, untuk Variabel X1 (Exterior) dan X2 (General Interior) tidak berpengaruh signifikan terhadap Variabel Y (Minat Beli Konsumen). Hasil dari penelitian ini berbeda dengan penelitian yang dilakukan oleh Meldarianda (2010) yang dilakukan di Bandung, Purwaningsih (2013) yang dilakukan di Kebumen, Nuridja (2014) yang dilakukan di Kecamatan Nusa Penida dan Sari (2014) yang dilakukan di Semarang. Hal ini disebabkan karena perbedaan lokasi penelitian dan kondisi pada saat pengambilan sampel.

\section{KESIMPULAN}

Variabel store layput dan interior display berpengaruh signifikan terhadap minat beli konusmen pada Distro Three Second di Kota Mataram. Hal ini dapat dilihat pada uji t yang menyatakan $t$ hitung masing-masing variabel store layput dan interior display $(2,771$; $2,873)>\mathrm{t}$ tabel $(1,975)$. Variabel general exterior dan general interior tidak berpengaruh signifikan terhadap minat beli konsumen pada Distro Three Second di Kota Mataram. Hal ini dapat dilihat pada uji $\mathrm{t}$ yang menyatakan $\mathrm{t}$ hitung masing-masing variabel general interior dan interior display $(0,592 ; 1,427)<\mathrm{t}$ tabel $(1,975)$. Dari tabel Coefficient kolom standardized coefficient beta tertinggi dimiliki oleh variabel Interior Display sebesar 0,229. Hal ini berarti variabel yang memiliki pengaruh dominan terhadap minat beli konsumen pada Distro Three Second di Kota Mataram yaitu variabel Interior Display. Sedangkan Coefficient kolom standardized coefficient beta terendah dimiliki oleh variabel exterior yait $u$ sebesar 0,044 .

\section{DAFTAR PUSTAKA}

Alma, Buchari. 2011. Manajemen Pemasaran dan Pemasaran Jasa. Bandung: Alfabeta. Azwar, Saifuddin. 2009. Penyusunan Skala Psikologi. Yogyakarta: Pustaka Pelajar.

Basri, Seta. 2012. Uji Validitas dan Reliabilitas, dalam http://setabasri01. Blogspot.com, di unduh tanggal 22 September 2015.

Berman, B. \& J. R. Evans. 2008. Retail Management: a strategic approach (8 $8^{\text {th }}$ ed.) Upper Saddle River: Pretice International, Inc.

Durianto, Darmadi. 2011. Strategi Menaklukkan Pasar Melalui Riset Ekuitas dan Perilaku Merek. Jakarta: Gramedia Pustaka Utama.

Engel, F.J., Blackwell, R.D \& Miniard, P.W. (1995). Perilaku konsumen Jilid 2, Edisi Keenam (terjemahan). Jakarta: Binarupa Aksara.

Foster, Bob. 2008. Manajemen Ritel. Bandung. Alfabeta.

Ghozali dan Fuad. 2005. Structural Equetion Modeling Teori Konsep \& Aplikasi dengan Program Lisrel 8.54. Badan Penerbit UNDIP. Semarang.

Idrus, Muhammad.2009. Metode Penelitian Ilmu Sosial (Pendekatan Kualitatif dan Kuantitatif Edisi Kedua). Jakarta: Erlangga.

Kotler, Philip. 2005. Manajamen Pemasaran, Jilid 1 dan 2. Jakarta: PT. Indeks Kelompok Gramedia.

Kreitner, R. \& Kinicki, A. 2005. Perilaku organisasi. Buku 1. Edisi kelima. Terj. Erly Suandy. Jakarta: Salemba Empat.

Meldarianda, Resty. 2010. Pengaruh Store Atmosphere terhadap Minat Beli Konsumeln pada Resort Café Atmosphere Bandung. Jurnal Bisnis dan Ekonomi. Vol. 17. No. 2. 
Rizky dan Yasin, 2014. Pengaruh Promosi Dan Harga Terhadap Minat Beli Perumahan Obama Pt.

Nailah Adi Kurnia Sei Mencirim Medan. Jurnal Manajemen \& Bisnis. Vol. 14. No.02.

Purwaningsih, Ayu. 2013. Pengaruh Suasana Toko Terhadap Minat Beli Konsumen Pada Swalayan Jadi Baru Di Kebumen: Skripsi pada Fakultas Ekonomi Muhammadiyah Purworejo.

Nuridja, Made. 2014. Pengaruh Suasana Toko (Store Atmosphere) Terhadap Minat Beli Konsumen Pada Toserba Nusa Permai di Kecamatan Nusa Penida. Skripsi pada Fakultas Ekonomi dan Bisnis Universitas Pendidikan Ganesha Singaraja Vol: 4 No: 1.

Sari, Desi A. 2014. Analisis Pengaruh Store Atmosphere Terhadap Minat Beli Konsumen Pada Pizza Hut Semarang: Skripsi pada Fakultas Ekonomi Universitas Pandanaran Semarang.

Tyas, Herti C., 2012. Analisis Sikap Konsumen Terhadap Iklan Rinso Di Televisi (Di Kelurahan Taman Sari Kecamatan Ampenan). Skripsi. Tidak Dipublikasikan. Universitas Mataram. 